\title{
Beliefs About the Permissibility of Abortion and Their Relationship to Decisions Regarding Abortion
}

\author{
Judith G. Smetana \\ University of Michigan
}

A questionnaire assessing beliefs about the permissibility of abortion was administered to 70 single women who had never been pregnant $(n=22)$ or who were deciding to terminate $(n=25)$ or continue $(n=23)$ an unplanned pregnancy. Respondents were given a list of 22 circumstances and asked to indicate the general permissibility and the permissibility for themselves of each item, in addition to indicating the most and least adequate circumstances for abortion. Factor analysis revealed similar structures of beliefs when women considered what was permissible for others as for themselves, although the factors reversed in importance in the two conditions. With the exception of one factor of the general permissibility of abortion, all the factors discriminated between women deciding to have abortions and women deciding to continue their pregnancies. The origin of these different judgments is discussed.

Abortion continues to be one of the most polarizing issues of this decade. While the 1973 Supreme Court ruling has established abortion as a private matter at the discretion of the individual woman, public debate is continuing, and the legality

This research was supported by Grant \#BNS76-83384 from the National Science Foundation and represents a portion of the research submitted in partial satisfaction of the requirements for the Ph.D. degree at the University of California, Santa Cruz. The author gratefully acknowledges the contributions of Drs. Nancy Adler, M. Brewster Smith, and Elliot Turiel. An earlier version of this paper was presented at a symposium on Current Research on Contraception and Abortion at the 86th Annual Convention of the American Psychological Association in Toronto, Canada. Requests for reprints should be sent to the author at the University of Michigan, Psychology Dept., 580 Union Drive, Ann Arbor, Michigan 48109. 
and widespread availability of therapeutic abortion is currently being challenged. In this context, research on attitudes towards abortion represents a particularly important area for current concern.

While many studies of attitude toward abortion have conceptualized attitudes as a unidimensional scale of favorability, various authors have posited the importance of a consideration of beliefs as a component of attitudes (Fishbein, 1963; Rosenberg, 1956). Such approaches have been profitably applied to studies of attitudes toward abortion (Gough, 1975; Smetana and Adler, in press; Werner, 1976). One such approach differentiates beliefs about abortion in terms of the circumstances in which respondents feel abortion ought or ought not to be permissible. This has provided a more detailed understanding of individual's beliefs about the legality of abortion. Most commonly, respondents are presented with items describing circumstances, such as rape or if the woman is unmarried, and asked to indicate whether or not the circumstance should be permissible. This method has been used to survey nationwide samples (Blake, 1971; Jones and Westoff, 1978; Lipson and Wolman, 1976) and analyze trends over time in attitudes toward abortion (Arney and Trescher, 1976; Evans, Selstad and Welcher, 1976; Jones and Westoff, 1978).

Although single teenagers' and young adults' attitudes towards abortion are directly relevant to public policy and the provision of abortion and contraceptive services, and although this group represents the largest consumers of abortion services (DHEW, 1977), attitudes toward abortion among single women in the childbearing age have been less frequently sampled than attitudes among the general population or among married women. This group provided the focus of the research reported in the present article. Judgments about a variety of permissible circumstances in which women should be able to obtain abortions were elicited from women making decisions about unwanted pregnancies, as were their judgments about the permissible circumstances in which they themselves would consider abortion. In addition, the beliefs differentiating women deciding to continue or terminate unplanned pregnancies were examined. In contrast to the methodology of previous studies, subjects were asked about the permissibility of a variety of circumstances about abortion, and the structure of beliefs was 
examined through the use of factor analysis. In addition, ratings of the adequacy of these beliefs were obtained.

\section{METHOD}

\section{Subjects}

Subjects were 70 single women, ranging in age from 13 to 31 . They were recruited from five family planning agencies and one high school continuation program for teenage mothers in a small university town in California. They were divided into three groups. The first group was composed of 25 women in first pregnancies deciding to have an abortion. The second group of 23 women (16 from the agencies and nine from the high school program) were in similar circumstances but deciding to continue their pregnancies. (Women were obtained from the high school program because of the difficulty in locating single women who intended to continue their first, unplanned pregnancies; all nine women were within the first five months of their pregnancy). The third group was composed of 22 never-pregnant women matched in age to the first two groups.

The groups did not differ in age, education, occupation or parents ${ }^{\prime}$ occupation as measured on the Index of Urban Status (Coleman and Neugarten, 1971), religious background, current religious preference, or whether or not they were living with their partners. They were, on the average, 20.8 years old, had some college education, and came predominantly from lower-middle class families. The sample was 36 percent Catholic, 40 percent Protestant, 15 percent Jewish or other religions, and nine percent atheist in religious background, and most of the sample were not living with their partners. Analyses of variance indicated that the groups differed in mothers' educational attinment, religious attendance, and length of gestation at the time of the interview. Never-pregnant subjects and subjects deciding to have an abortion reported never attending church, and their mothers had some college education; subjects electing abortion were, on the average, 7.48 weeks from their last menstrual period. Subjects continuing their pregnancies reported attending church one to two times a year; their mothers were high school graduates; and they were, on the average, 14.13 weeks from their last menstrual period. The difference in number of weeks from last menstrual period was still significant when subjects from high school continuation program were excluded from the analyses.

\section{Procedure}

Single women in first, unplanned pregnancies were contacted and invited to participate by counselors at the clinics advising them of their 
JUDITH G. SMETANA

pregnancy test outcome. Participation from women in the high school program was obtained by their teacher. The questionnaires were completed by consenting women at an interview scheduled for within a few days of the initial contact. At this time, an intensive interview designed to examine more specifically the reasoning and decisionmaking about abortion was also administered. For women having abortions, the interview occurred prior to their procedures.

\section{Questionnaire}

The questionnaire contained a list of 22 circumstances in which a woman may want to obtain an abortion. The items represented a variety of circumstances concerned with responsibility for the pregnancy, if, for example, the pregnancy occurred as a result of rape or through birth control failure; circumstances concerned with the woman's welfare, for example, the woman's life would be endangered; or circumstances related to the unborn child's welfare, such as that the child would be adopted. These items were selected from a review of other research and pilot tested on a sample of university undergraduate women. The items were repeated three times with three different sets of instructions. The first two sets of instructions asked subjects to indicate (a) the circumstances in which abortion generally should be permissible, and (b) the circumstances in which they would consider abortion permissible for themselves. For each circumstance, they were asked to indicate whether abortion was never justified, or whether it was justified through the first, second, or third trimester of a pregnancy. Both sets of responses were scored on a scale ranging from zero (not at all) to three (through the third trimester). The third set of instructions asked subjects to indicate the five most and five least adequate reasons for having an abortion. These data were assigned ranks. A score of one indicated the most adequate reasons, a score of three indicated the least adequate reasons, and a score of two was assigned to the remaining 12 circumstances. Subjects were instructed to consider the circumstances and times that they considered abortion justified rather than to demonstrate thier factual knowledge about the current legal status of abortion.

\section{RESULTS}

Ratings for Women in General

Principal components factor analysis with varimax rotation was performed on subjects' ratings of the general permissibility of abortion. A factor loading of .450 and above and a high loading on only one factor were used as criteria for inclusion of an item in 
a factor. Using this method, the factor analysis yielded three factors, composed of 21 variables, that discriminate between the hard reasons for abortion, that is, those reasons that are essentially beyond the woman's control; the soft reasons for abortion, that is, those that are under her control; and a set of outcome variables related to the quality of the unborn child's life. The items included in each factor and the factor loading scores are presented in Table 1.

As can be seen, the first factor, which accounted for 55 percent of the variance, was composed of 11 variables that represent a variety of soft reasons for a woman to want to obtain an abortion, such as that she is unmarried, that the child would strain her marriage, or that the couple was careless about using birth control. The second factor, which accounted for 10.5 percent of the variance, included the variables that are generally considered hard reasons for abortion, such as potential deformity, or that the pregnancy is a threat to the woman's health. Also included was an item indicating that the child would be unwanted. The four variables included in the third factor, accounting for 7.3 percent of the variance, concerned the quality

TABLE I

Factors and Factor Loadings of the Generally Permissible

Circumstances of Abortion

\begin{tabular}{|c|c|}
\hline \multicolumn{2}{|l|}{ Factor 1: $55 \%$ of the varfance } \\
\hline The pregnancy was planned, bur the woman changed her find & .845 \\
\hline The couple was careless about using birth control & .834 \\
\hline The pregnancy occurred through birth control failure & .831 \\
\hline Having the child now would be an inconvenience & .777 \\
\hline Having the child now would hurt the woman's career & .775 \\
\hline The wowan is unmarried & .757 \\
\hline The voman did not know about birth control & .741 \\
\hline The woman does not want the child but her partner does & .740 \\
\hline The child would strain the martiage or relationship & .708 \\
\hline The woman uses abortion as her method of birth control & .564 \\
\hline The wounan (or fanily) lan't able to care for the child financially & .546 \\
\hline \multicolumn{2}{|l|}{ Eactor 2: $10.5 \%$ of the variance } \\
\hline Continulng the pregnancy would endanger the wonan's physical health & .891 \\
\hline Continuing the pregnancy would endanger the woman's mental health & .882 \\
\hline Continuing the pregnancy would endanger the woman's life & .817 \\
\hline There is a good chance the child would be born defective & .813 \\
\hline The child would be likely to grow up in an institution & .666 \\
\hline The child would remain in the family but be unwanted & .615 \\
\hline \multicolumn{2}{|l|}{ Eactor 3: 7,32 of the variance } \\
\hline The child would grow up with only one parent & .839 \\
\hline The child would grow up in poverty & .791 \\
\hline The woman wants the chtld but her partner does not & .736 \\
\hline The child would be adopted & .724 \\
\hline
\end{tabular}


of the unborn child's life, such as that the child would be adopted.

Factor scores, obtained by assigning each item included in the factor a weight of one and all others a weight of zero, were used to compare differences between the groups in response to the items. Analyses of variance revealed that subjects having abortions and never-pregnant subjects were significantly more permissive in their judgments about the permissible soft and hard circumstances for abortion than subjects continuing their pregnancies (Factor $1: F=5.53, p<.01$; Factor $2: F=6.58, p<$ $.01)$; the groups did not differ in their judgments about the items composing Factor $3(\mathrm{~F}=1.70, \mathrm{~ns})$. The mean length of acceptability of abortion for the items in a given factor, calculated from the factor scores (see Table 2), indicates that while, on the average, subjects found the hard circumstances permissible reasons for abortion at least through the first trimester of pregnancy, acceptance of the soft circumstances and the outcome circumstances (Factors 1 and 3 ) varied. While the abortion and never-pregnant groups found these reasons acceptable at least through the first trimester of a pregnancy, acceptability for subjects in the continuing group was, on the average, more limited.

\section{Respondent's Ratings for Herself}

The same procedures were used to generate factors and factor scores for the data on the permissibility of abortion for the respondent. This factor analysis yielded four factors, composed of 18 variables (see Table 3 ). Included in the first factor were the same six variables, considered hard reasons, that clustered

TABLE 2

Means and analyses of variance for faccors

of the general permissibility of abortion

\begin{tabular}{|c|c|c|c|c|c|c|c|c|}
\hline & \multicolumn{3}{|c|}{$\frac{\text { Mean pezmiasioility of abortion }}{\text { (by trimesters) }}$} & \multicolumn{3}{|c|}{ Mean factor scores } & \multirow[b]{2}{*}{ F-ratio } & \multirow[b]{2}{*}{$P$} \\
\hline & $\begin{array}{l}\text { Abortion } \\
\qquad N=25\end{array}$ & $\begin{array}{c}\text { Continue } \\
\mathrm{N}=23\end{array}$ & $\begin{array}{l}\text { Never-Eregnant } \\
\qquad N=22\end{array}$ & $\begin{array}{c}\text { Abortion } \\
N=25\end{array}$ & $\begin{array}{c}\text { Continue } \\
N=23\end{array}$ & $\begin{array}{l}\text { Never-Pregnant } \\
\qquad \mathrm{N}=22\end{array}$ & & \\
\hline FACTOR 1 & 1.72 & .89 & 1.45 & $18.88 *$ & 9.85 & 15.95 & 5.53 & .01 \\
\hline FAC'COR 2 & 2.59 & 1.83 & 2.26 & $15.56 *$ & 11.00 & 13.43 & 6.58 & .01 \\
\hline FACTOR 3 & .98 & .59 & 1.04 & 3.92 & 2.35 & 4.14 & 1.70 & ns \\
\hline
\end{tabular}

*Both the Abortion \& Never-pregnant groups differed significantly from the Continuing group. 


\begin{tabular}{|c|c|}
\hline & \\
\hline Continuing the pregnancy would endanger the toman's physical health & .782 \\
\hline Continuing the pregnancy would endanger the womar's merital health & .767 \\
\hline There is a good chance the child would be born defective & .765 \\
\hline Continuing the pregnancy would endanger the woman's iffe & .747 \\
\hline The child would be likely to grow up in an institution & .720 \\
\hline The child would remain in the famtly but be unwanted & .662 \\
\hline \multicolumn{2}{|l|}{ Eactor 2: $8.5 \%$ of the variance } \\
\hline The women uses abortion as her method of birth control & .784 \\
\hline The pregnancy was planned but the woman changed her infnd & .668 \\
\hline The child would be adopted & .657 \\
\hline \multicolumn{2}{|l|}{ Factor 3: $7.0 \%$ of the variance } \\
\hline The couple was careless about using birth control & .770 \\
\hline The pregnancy occurred through birth control failure & .733 \\
\hline The woman (or fanily) isn't able ta care for the child financialiy & .706 \\
\hline The woman is unmarried & .701 \\
\hline The woman did not know about birth control & .679 \\
\hline The pregnancy occurred as a kesult of rape & .556 \\
\hline \multicolumn{2}{|l|}{ Factor 4: $5.3 \%$ of the vartance } \\
\hline The child would grow up with only one parent & .821 \\
\hline The woman wants the child but her partner does not & .814 \\
\hline The child would grow up in poverty & .605 \\
\hline
\end{tabular}

together in the analyses for the general permissibility of abortion. While this factor accounted for only a small percent of the variance (10.5 percent) and was the second factor to emerge in the previous analysis, these circumstances accounted for 52 percent of the variance and emerged as the first factor when the subjects considered the circumstances in which they believed abortion was justified for themselves. The items composing Factor 1 in the previous analysis now factored into two clusters of three and six variables, together accounting for only 15 percent of the variance, which differentiate between what might be considered more casual uses of abortion, such as abortion as a method of birth control or because the woman changed her mind, and more practical soft circumstances, such as financial difficulty. Surprisingly, among these soft circumstances is also included the item related to rape, which did not load highly in the factor analysis for the general permissibility of abortion. The fourth factor is similar to the third factor in the analysis for women in general, and includes three variables concerning the quality of life of the unborn child.

Analyses of variance comparing the three groups in res- 
JUDITH G. SMETANA

TABLE 4

Means and analyses of variance for factors

of the permissibilify of abortion for respondent

\begin{tabular}{|c|c|c|c|c|c|c|c|c|}
\hline & \multicolumn{3}{|c|}{$\begin{array}{l}\text { Mean permissibility of abortion } \\
\text { (by trimestexs) }\end{array}$} & \multicolumn{3}{|c|}{ Mean factor scores } & \multirow[b]{2}{*}{ F-ratio } & \multirow[b]{2}{*}{ p } \\
\hline & $\begin{array}{r}\text { Abortion } \\
\operatorname{Nm} 25\end{array}$ & $\begin{array}{c}\text { Cont inue } \\
\mathrm{N}=23\end{array}$ & $\begin{array}{l}\text { Never }- \text { Pregnant } \\
\quad \mathrm{N}=22\end{array}$ & $\begin{array}{c}\text { Abortfon } \\
N=25\end{array}$ & $\begin{array}{c}\text { Continue } \\
x=23\end{array}$ & $\begin{array}{l}\text { Never-Pregnant } \\
N=22\end{array}$ & & \\
\hline FACTOR 1 & 2.35 & 1.32 & 1.80 & 14.08 & 7.90 & 10.81 & 9,97 & .0001 \\
\hline Factor 2 & 1.01 & .30 & .78 & 3.04 & .90 & 2,33 & 5.04 & .01 \\
\hline FACTOR 3 & 1.71 & .38 & 1.17 & 10.28 & 2.25 & 7.00 & 25.49 & .0001 \\
\hline FACTOR 4 & .71 & .17 & .73 & 2.12 & .50 & 2.19 & 5.34 & .01 \\
\hline
\end{tabular}

ponse to the items composing each factor were significant for all factors (Factor 1: $F=9.97, p<.0001$; Factor $2: F=5.04, p<.01$; Factor $3: F=25.49, p<.0001$; Factor $4: F=5.34, p<.01$; see Table 4). In all four analyses, subjects having abortions were significantly more permissive about the reasons they would consider abortion justified for themselves than subjects continuing their pregnancies. In addition, nonpregnant subjects were less permissive than subjects having abortions but were more permissive than subjects continuing their pregnancies in their responses to items composing Factor 1 and Factor 3 . They did not differ significantly from either group in their responses to items composing Factors 2 and 4 . An examination of the mean times in which abortion would be permissible for items in each factor reveals that, on the average, subjects continuing their pregnancies found all reasons except the hard circumstances unacceptable for themselves, while subjects having abortions indicated approval at least through the first trimester of a pregnancy for the soft and hard reasons, on the average. Both the abortion and never-pregnant groups did discriminate between the two sets of soft circumstances, however, and indicated less approval of items related to a more casual use of abortion, such as abortion as a birth control method, than items indicating more practical circumstances for wanting an abortion, such as because of birth control failure or financial difficulty.

Ratings of the Adequacy of Circumstances for Abortion

Kruskal-Wallis analyses of variance comparing the three groups' ratings of the adequacy of each item revealed that only 
two items, "having the child now would hurt the woman's career," and that "the child would have to be adopted," discriminated between the three groups $\left(x^{2}=7.38, p<.05\right.$; $\mathrm{x}^{2}=9.06, \mathrm{p}<.05$, respectively). Subjects continuing their pregnancies considered both items less adequate than subjects having abortions. All three groups agreed in their judgments that the hard reasons, such as rape and that the woman's life or physical health would be endangered, are the most adequate circumstances for abortion. There was also strong agreement that four circumstances, that the woman is unmarried, that she changed her mind, that the pregnancy is inconvenient, or that she uses abortion as a method of birth control, are the least adequate circumstances for wanting an abortion.

\section{DISCUSSION}

The present study obtained judgments about a variety of circumstances in which abortion ought or ought not be permissible from a sample of unmarried women in the childbearing age. In contrast to the methodology of previous studies, the structure of these beliefs was examined through the use of factor analysis. The findings indicated that the structure of beliefs among the present sample parallels distinctions between hard and soft reasons for abortion (Arney and Trescher, 1976; Jones and Westoff, 1978) and the two response patterns observed by Arney and Trescher (1976) but, further, distinctions between the soft circumstances as permissible reasons for abortion were found.

That roughly the same factors emerged in the factor analyses of responses for women in general and for the respondent herself suggests that these factors function somewhat similarly when women consider abortion for themselves and for others. Important differences emerged, however. All groups were less permissive about the acceptable times during which they would consider abortion justified for themselves than for others, indicating that abstract judgments about abortion are more liberal than individuals' judgments about what would be justified for themselves. One argument used by antiabortion forces is that the availability of abortion will lead to its increased acceptance and casual use (Adler and Everett, 1978). These findings, in conjunction with the adequacy ratings, as well as the 
present finding that women discriminate between more or less casual use of abortion and are not very permissive about its casual use, provide countersupport for this argument.

The present findings also indicated that the soft and hard reasons reversed in importance when women considered what is permissible for others as opposed to themselves. These findings can best be understood in light of recent trends in abortion attitudes, most recently observed by Jones and Westoff (1978) and the present findings on the average times in a pregnancy that subjects find the items composing each factor acceptable. Nationwide trends in abortion attitudes have revealed that, while level of approval for the hard circumstances has remained relatively high, the shift in approval has been greatest among the least restrictive circumstances. However, analyses of individual as opposed to aggregate data also show the greatest polarization among these circumstances (Jones and Westoff, 1978). It appears that the present factor analyses tapped this greater salience of the soft as opposed to hard circumstances when subjects consider what should be permissable for others. Analyses of the acceptability of these items by group reveals, however, that their salience reflects divergent beliefs; that is, respondents having abortions and never-pregnant respondents indicate that abortion should be available through the first, if not the second, trimester of a pregnancy, while many of the respondents who were continuing their pregnancies indicate that these circumstances are not at all permissible.

Consistent with other findings (Evans et al., 1976), differences in level of acceptance for the clusters of soft reasons were related to decisions. Women having abortions were found to be consistently more permissive in their judgments about the general acceptability of abortion than women having their child. These findings raise questions about the origins of these differences. Both Evans et al. (1976) and other survey data (Arney and Trescher, 1976; Jones and Westoff, 1978) have indicated that religious commitment, as measured by religious attendance, and education differentiate between those who are more or less approving of abortion. That is, those who are more religiously committed and less educated tend to be less approving of abortion. The groups studied here, selected on the basis of their decisions about their unplanned pregnancies, did differ somewhat in demographic composition. On the basis of 
these previous findings, one might suspect that the differences are the product of demographic variables and, in particular, differences in religious attendance, as the present sample was relatively homogeneous with respect to education.

The same question may be raised concerning subjects' beliefs about the permissibility of abortion for themselves. The finding that women having abortions were consistently more permissive than women continuing their pregnancies when considering the circumstances when abortion is justified for themselves is not surprising, since subjects having abortions indicated, in the interview data collected at the same time, that their reasons for deciding to have an abortion could be classified among the soft reasons presented in the questionnaire. In contrast, many of the subjects who chose to continue their unplanned pregnancies did so out of their belief that abortion is rarely justified. In other research, when demographic variables have been found to differentiate between women deciding to have an abortion or continue their pregnancies, it has been assumed that they are the most powerful determinants of the abortion decision (Evans et al., 1976; Steinhoff et al., 1972). However, the data collected through intensive interviews indicates that judgments about abortion are embedded in different cognitive and developmental structures (Smetana, 1978). That is, women's reasoning about abortion could be reliably distinguished between abortion as a moral issue (Kohlberg, 1969) or an issue related to justice concerns involving a weighing of two lives, abortion as a personal issue (Nucci, 1977) or an issue related to the self-determination of the individual, and the coordination or lack of coordination between these two domains. These structures were found to be highly related to women's decisions; moral reasoners were more likely to continue their pregnancies while personal reasoners were more likely to terminate their pregnancies. Distinctions in reasoning were also found to be a more powerful predictor of decisions than demographic variables, including religious attendance (Smetana, 1978).

These findings have several implications. The first is that, in understanding antecedents of attitudes towards abortion, the role of psychological variables as well as demographic variables requires further study. Second, these data also suggest that attitudes toward abortion are multifaceted, and that similar responses to questionnaire items can be the product of different 
underlying reasoning, or cognitive structures. That is, acceptance or rejection of different circumstances as permissible ones for abortion may arise from concerns related to the woman's autonomy, welfare, and health, or justice concerns related to issues of life. Not only would interpretations of abortion survey findings be greatly improved if these different concerns were distinguished, but they also have different policy-relevant implications. This suggests that future research on the permissibility of abortion needs to go beyond the present assessment of the content of beliefs and their acceptability to an understanding of the reasoning underlying these responses.

\section{REFERENCES}

Adler, N. \& Everett, W. Abortion: Public policy, public opinion, and behavioral research. Population and Environmental Psychology Newsletter, 1978, 5 (1), 24-28.

Arney, W.R. \& Trescher, W.H. Trends in attitudes toward abortion. Family Planning Perspectives, $1976,8(3), 117-124$.

Blake, J. Abortion and public opinion: The 1960-1970 decade. Science, 1971, 171, 540549.

Coleman, R. \& Neugarten, B. Social Status in the City. San Francisco: Jossey-Bass, 1971.

Center for disease control, DHEW. Abortion Surveillance, Annual Summary, 1975, Atlanta, 1977.

Evans, J.R., Selstad, G. \& Welcher, W.H. Teenagers: Fertility control, behavior, and attitudes before and after abortion, childbearing or negative pregnancy test. Family Planning Perspectives, 1976, 8(4), 192-200.

Fishbein, $M$. An investigation of the relationships between beliefs about an object and the attitude toward that object. Human Relations 1963, 16, 233-240.

Gough, H.G. An attitude profile for studies in population psychology. Journal of Research in Personality, 1975, 9, 122-135.

Jones, E.F. \& Westoff, C.F. How attitudes towards abortion are changing. Journal of Population, 1978, 1(1), 5-21.

Kohlberg, L. Stage and sequence: The cognitive-developmental approach to socialization. In D. Goslin (ed.) Handbook of Socialization Theory and Research. New York: Rand McNally \& Co, 1969.

Lipson, G. \& Wolman, D. Polling Americans on birth control and population. FamilyPlanning, Perspectives, 1972, 4(1), 39-42.

Nucci, L. Social development: Personal, conventional and moral concepts. Unpublished Ph.D. dissertation, University of California, Santa Cruz, 1977.

Rosenberg, M.J. Cognitive structure and attitudinal affect. Journal of Abnormal and Social Psychology, 1956, 53, 367-372.

Smetana, J. Personal and moral concepts: A study of women's reasoning and decisionmaking about abortion. Unpublished Ph.D. Dissertation, University of California, Santa Cruz, 1978.

Smetana, J. \& Adler, N. Decision-making regarding abortion: An expectancy $x$ value Analysis. Journal of Population, in press.

Steinhoff, P.G., Smith, R.G. \& Diamond, M. Characteristics and motivations of women receiving abortions. Sociological Symposium, 1972, 8, 83-89.

Werner, P. A canonical correlation analysis of beliefs and attitudes regarding abortion. Paper presented at the 56th Annual Convention of the Western Psychological Association, Los Angeles, 1976. 